the research to the end; extreme care in observation and strict attention to detail; careful recording of observations, which should be done at the earliest possible moment; thorough belief in the importance of the particular research, amounting even to enthusiasm; conscientiousness.

Many of these desirable qualities will at once commend themselves to you; they need no more than enumeration. But you may wonder why I have set down others of them. For instance, what has conscientiousness to do with research any more than it has to do with any other of the affairs of life? Do I mean that an investigator should be honest and not appropriate or use unfairly the work of other investigators? Oh, no! I assume such honesty as this in every investigator. The conscientiousness of which I speak is of the worker to himself and his own work. In this way. A worker has been engaged in a research during many months. He has made many experiments and observations, and they have all gone to prove the correctness of the result at which he has arrived. But there is still one experiment which it would be well to try. $\mathrm{He}$ tries it, and curiously it does not turn out quite right. He puts two and two together and they do not make four. And everyone agrees with "The Professor in the Case" that two and two do make four, "not some times, but all the time." Now is the moment when his conscientiousness should come into play. The temptation is overwhelming to explain the failure by some fault in technique, and to set the result of that experiment on one side rather than to repeat it again and again as he ought certainly to have done. Had he done so it would again have failed, and he would have learned in the end, not that two and two do not make four, but that one of his twos was not a two, and he would have avoided publishing that result of his research which was afterwards discovered to be incorrect by a more careful and conscientious worker. It must always be borne in mind that the mischief of a faulty result does not end with that research, but may be the starting point of a long series of equally faulty results.

\section{GEOGRAPHY AT THE BRITISH} ASSOCIATION.

I $\mathrm{N}$ his presidential address Colonel Close, the recently appointed Director-General of the Ordnance Survey, raised again the oft-debated question, "What is geography?" His contention that geography, apart from cartography, cannot be treated as a science in itself, but must serve as a common meeting-place and popularising medium for various other sciences, will certainly not be accepted by modern geographers without considerable modification and amplification.

Prof. Herbertson exhibited and explained a new series of thermal maps which he has constructed to show the actual mean temperatures prevailing over the globe instead of the temperatures reduced to sea-level, as indicated on the ordinary meteorological maps. Among other papers on cartography were two by Mr. A. R. Hinks, one dealing with the use of colour on contour maps, and the other with the most suitable projections for atlas maps. Captain Henrici discussed the present state of our knowledge-not altogether satisfactory-of the mean sea-level round our coasts, and arrived at the conclusion that there is no evidence, from the observations made, to justify the belief that mean sea-level is not constant around the British Isles. Captain Henrici also contributed a note on the height of Ruwenzori as determined by him from observations made by Captain Jack. His result is $\mathrm{I} 6,8 \mathrm{O} \mathrm{I} \cdot 3 \pm 5 \cdot 3$ feet.

Among the papers on physical geography, two of the most interesting were contributed by Prof. J. W. Gregory and Prof. O. Pettersson. The former showed that while waterfalls have generally been regarded as destructive, they may in certain circumstances be constructive and act as agents of deposition instead of denudation. In support of this he instanced certain waterfalls in Dalmatia, Bosnia, and Herzegovina. In the former country, for example, the Kerka Falls are due to a barrier of calcareous tufa which the Kerka River has built across its valley. Prof. Pettersson discussed the deep-water movements in the Skagerrak, and showed that they occurred when the earth

NO. 2 I 88 , VOL. 87 ] is in perihelion. His theory is that these waves are in fluenced by the phases of the moon, but still more by its declination and distance from the earth. $\mathrm{He}$ also showed that since 1753 the herring fishery on the coasts of Sweden has been most prolific in years of maximum declination and least prolific in years of minimum declination, a resuit which he attributes to the influence of the movements in the deep water. Captain Rawling gave an account of the British expedition to Dutch New Guinea, and showed some excellent views of the Nassau Range with its precipitous front more than eighty miles in length and from 8000 to 10,500 feet in sheer height.

The work of the section was concluded by an interesting discussion on aëronautical maps. M. Lallemand described the resolutions recently adopted at his suggestion by the Permanent Committee for Aërial Navigation of the Public Works Department of the French Government on the production of an international air-map, and the establishment of marks required by aviators and aëronauts. Captain Lyons followed with certain general suggestions for the construction of aëronautical maps, and in the subsequent discussion several officers of the air battalion and others took part. A full report of this discussion is to be published in The Geographical Journal.

\section{MECHANICAL SCIENCE AT THE BRITISH ASSOCIATION.}

THE meeting of the Mechanical Science Section of the British Association at Portsmouth, under the presidency of so distinguished a naval architect as Prof. Harvard Biles, was naturally the occasion for a very interesting programme of papers relating to many branches of marine engineering work ranging over a wide field of applied science, and dealing with some of the most important developments which are now engaging the attention of engineers and men of science in this branch of engineering activity.

The programme contained important papers on the rolling of ships, by the president, the gyro-compass, electrical steering and propulsion of ships, and the developments of wireless telegraphy, especially in its relation to naval problems; while in the purely mechanical section the advances in methods of generating motive power were dealt with in a series of related papers on internal-combustion engines and the superheated steam engine. Not only had the members who attended this section an opportunity of hearing these papers and the very interesting discussions to which they gave rise, but all the sections took the opportunity so kindly afforded them by Admiral Sir A. W. Moore of witnessing, from a battleship which carried them into the Solent, a combined attack by numerous torpedoboats and submarine vessels with as near an approach to the conditions of naval warfare as practicable.

The interest which all members of the association take in the practical applications of scientific discovery to naval matters was manifested by the close attention to the wonderful evolutions and diving performances of the attacking vessels, while the swift and silent attack of the torpedoes, invariably marked by the final dull thud of impact as each one found its mark, gave a thrill of the possibilities of actual warfare not easily forgotten.

Although the proceedings of the section were so largely devoted to naval matters, other subjects of importance also claimed the attention of the members, like the non-stop train, the peculiar corrugations produced on rails by the long-continued passage of trains; while subjects of more general interest were afforded by papers on smoke abatement, and the possibilities of the manufacture of nitrogen products in this country by electric power, a question of great importance in connection with agriculture and the manufacture of explosives.

The discussion between Sections A and G on aërial flight at the Monday's meeting attracted a very large gathering, and has been dealt with in a separate article (September 28 , p. 439).

We now turn to a more detailed examination of the papers in their order, and the discussions to which they gave rise. The president's address, on the rolling of ships, 